\title{
Pemberdayaan Masyarakat Dimasa Pandemi Melalu Pelatihan Pembuatan Handsanitizer Dan Pelatihan Pembuatan Coklat Desa Tamaila Utara
}

\author{
Yayu Indriati Arifin', Abdi Gunawan Djafar ${ }^{2}$ \\ ${ }^{1,2}$ Universitas Negeri Gorontalo, Jl. Jend. Sudirman No.6, Dulalowo Timur, Kota \\ Tengah, Kota Gorontalo, Gorontalo 96128, Indonesia. \\ email: yayu arifin@ung.ac.id
}

\begin{abstract}
Tamaila Utara village is one of the villages that became the fostered villages of the Gorontalo State University so that around 35 UNG students were sent to this village to carry out the GEF-SGP UNG Community Service Program. The core program carried out in this village is carried out using training methods. This handsanitizer-making training program and chocolate-making training were attended by North Tamaila Village government staff, youth and North Tamaila Village communities, the program which was run for one day received a good and enthusiastic response from the community of North Tamaila Village. The materials used for the handsanitizer training program are betel leaf and lime juice, these ingredients are very easy to obtain and the manufacture is also very easy. For the training material, cocoa uses cocoa pods that are taken directly from one of the hamlets in the village of Tamaila Utara, namely Tumba. TAMANTIS became a handsanitizer product resulting from the Handsanitizer training and CHOCO TUMBA became the product of the chocolate training carried out by GEF-SGP KKN students in the North Tamaila Village.
\end{abstract}

Keywords: GEF-SGP KKN; North Tamaila; Handsanitizer; Chocolate

\begin{abstract}
Abstrak
Desa tamaila utara merupakan salah satu desa yang menjadi desa binaan Universitas negeri gorontalo sehingganya sekitar 35 mahasiswa/i UNG di turunkan didesa ini untuk melaksanakan program KKN GEF-SGP UNG. Program inti yang dilaksanakan didesa ini dilakukan dengan menggunakan metode pelatihan. Program pelatihan pembuatan handsanitizer dan pelatihan pembuatan coklat ini diikuti oleh staf pemerintah desa tamaila utara, pemuda dan masyarakat desa tamaila utara, program yang di jalankan selama satu hari ini mendapatkan respon baik dan antusias dari masyarakat desa tamaila utara. Bahan yang digunakan untuk program pelatihan pembuatan handsanitizer yaitu daun sirih dan perasan jeruk, bahan ini sangat mudah didapat dan pembuatannya juga sangat mudah. Untuk bahan pelatihan coklat menggunakan buah kakao yang diambil langsung dari salah satu dusun dari desa tamaila utara yakni dusun tumba. TAMANTIS menjadi produk handsanitizer yang dihasilkan dari pelatihan Handsanitizer dan CHOCO TUMBA menjadi produk dari pelatihan coklat yang dilaksanakan oleh mahasiswa KKN GEF-SGP desa tamaila utara.
\end{abstract}

Kata Kunci: KKN GEF-SGP; Tamaila utara; Handsanitizer; Coklat 
(C) 2021 Yayu Indriati Arifin, Abdi Gunawan Djafar

Under the license CC BY-SA 4.0

Correspondence author: Yayu Indriati Arifin, yayu arifin@ung.ac.id, Gorontalo, and Indonesia

\section{PENDAHULUAN}

Kuliah Kerja Nyata (KKN) adalah salah satu media bagi mahasiswa untuk mengaplikasikan teori-teori yang dimilikinya ke dalam sebuah wujud nyata pengabdian kepada masyarakat. KKN juga merupakan bentuk konkrit dari pengalaman yang mencakup tri dharma perguruan tinggi yaitu pendidikan, penelitian, dan pengabdian kepada masyarakat. Dalam hal ini, mahasiswa diperankan sebagai problem solver, motivator, fasilitator, dan dinamisator dalam proses penyelesaian masalah dan pembangunan/pengembangan masyarakat. Melalui pembaruan konsep tersebut, kehadiran mahasiswa sebagai intelektual muda diharapkan mampu mengembangkan diri sebagai agen atau pemimpin perubahan yang secara cerdas dan tepat menyelesaikan masalah yang dihadapi masyarakatnya.

Program yang dilaksanakan tiap perguruan tinggi berbeda-beda tergantung pada disiplin ilmu yang terkait serta kebutuhan masyarakat dari daerah yang dituju sebagai tempat pelaksanaan KKN. Program yang dibuat dapat terbagi menjadi program umum seperti peringatan hari besar, pemberdayaan masyarakat, dan program khusus yang terkait tema besar suatu tim KKN. Beberapa tema khusus KKN antara lain seperti kesehatan dan sumber daya alam. Pada tahun 2020 ini KKN Universitas Negeri Gorontalo dilaksanakan pada tiga Kabupaten di Provinsi Gorontalo, yang terbagi lagi atas beberapa kecamatan dan desa. 
Desa Tamaila Utara adalah salah satu desa inovasi yang ditetapkan oleh PDTT, serta merupakan desa binaan dari Universitas Negeri Gorontalo. Dengan latar belakang desa sebagai desa inovasi dan desa binaan Universitas Negeri Gorontalo, maka perlu adanya pengabdian dari universitas sebagai bentuk implementasi tri dharma perguruan tinggi. Pengabdian yang dilakukan oleh Universitas Negeri Gorontalo terhadap desa binaan ini adalah dalam bentuk Kuliah Kerja Nyata (KKN) yang berfokus pada bidang kesehatan dan sumber daya alam.

Pandemi Covid-19 masih terus berlanjut, tentunya kesehatan tubuh merupakan aspek penting yang harus diperhatikan oleh setiap individu. Salah satu cara yang efektif untuk menjaga kesehatan tubuh adalah menjaga kebersihan, salah satunya adalah kebersihan tangan karena tangan adalah salah satu anggota tubuh yang sangat berperan penting dalam beraktivitas sehari-hari. Masyarakat tidak sadar bahwa pada saat beraktivitas tangan sering kali terkontaminasi dengan mikroorganisme karena tangan menjadi perantara masuknya mikroba ke saluran cerna. Mencuci tangan merupakan langkah awal untuk menghindari berbagai jenis kuman penyebab penyakit infeksi tetapi langkah ini sering kali diabaikan ataupun terlewatkan begitu saja. Membersihkan tangan dari mikroorganisme tidak hanya dapat dilakukan dengan mencuci tangan pakai sabun, ada cara praktis dengan menggunakan hand sanitizer yang pada umumnya masyarakat desa belum mengetahuinya. Hand sanitizer dapat dibuat dari bahan alam yang ada, sehingga tidak memakan biaya untuk mendapatkan pembersih tangan praktis tersebut. 
Potensi sumber daya alam yang ada di Desa Tamaila Utara dapat dimanfaatkan untuk keperluan pembangunan. Hasil pertanian yang melimpah di Desa Tamaila Utara dapat digunakan sebagai peningkatan hasil sektor perekonomian desa. Kurangnya pengetahuan masyarakat mengenai pengolahan sumber daya alam yang dapat menghasilkan nilai ekonomi yang lebih menjadi salah satu masalah yang ada di Desa Tamaila Utara. Dengan adanya program Kuliah Kerja Nyata Universitas Negeri Gorontalo maka dimaksudkan mahasiswa dapat menangani permasalahan yang ada di Desa Tamaila Utara.

\section{METODE PELAKSANAAN}

Metode pelaksanaan program KKN GE-SGP dalam kegiatan pemberdayaan ini berupa pelatihan pada aspek kesehatan dan ekonomi dengan materi pokok ( pelatihan pembuatan hand sanitizer dan pelatihan pembuatan coklat).

Adapun program pendukung/tambahan berupa sosialisasi PHBS dan Kampanye 3M pencegahan covid-19, penataan lingkungan, desain embung, pelatihan pembuatan sabun dan pekan olahraga desa tamaila utara ( PORDES TAMUT).

\section{HASIL DAN PEMBAHASAN}

Hasil

Program kerja utama dari dilaksanakannya KKN GEF-SGP UNG ini terbagi menjadi 2 program inti, yakni Pelatihan Pembuatan Hand Sanitizer dari bahan alami dan Pelatihan Pembuatan Cokelat dengan nama produk Choco Tumba pada masyarakat Desa Tamaila Utara. 


\subsection{Program Inti KKN GEF-SGP UNG}

No

Waktu

Program Inti

Pelaksanaan

Peserta

Ket

1. Pelatihan Pembuatan Sabtu, 19 Aparat

Hand Sanitizer

september desa dan

(TAMANTIS)

2020

karang

taruna

2. Pelatihan Pembuatan Sabtu,19 Masyarakat

Cokelat (Choco Tumba) september dan ibu PKK

2020

Pada program kerja tambahan yang dilaksanakan Peserta KKN GEF-SGP UNG terdiri dari beberapa program yang mempertimbangkan kebutuhan dan permintaan masyarakat yang dimuat dalam tabel dibawah ini diantaranya yaitu:

\subsection{Program Tambahan KKN GEF-SGP UNG}

\begin{tabular}{|c|c|c|c|c|}
\hline \multirow[t]{2}{*}{ No } & \multicolumn{4}{|c|}{ Waktu } \\
\hline & Program Inti & Pelaksanaan & Peserta & Ket \\
\hline 1. & $\begin{array}{l}\text { Pelatihan Pembuatan } \\
\text { Hand Sanitizer } \\
\text { (TAMANTIS) }\end{array}$ & $\begin{array}{l}\text { Sabtu, } 19 \\
\text { september } \\
2020\end{array}$ & $\begin{array}{l}\text { Aparat } \\
\text { desa dan } \\
\text { karang } \\
\text { taruna }\end{array}$ & \\
\hline 2. & $\begin{array}{l}\text { Pelatihan Pembuatan } \\
\text { Cokelat (Choco Tumba) }\end{array}$ & $\begin{array}{l}\text { Sabtu,19 } \\
\text { september } \\
2020\end{array}$ & $\begin{array}{l}\text { Masyarakat } \\
\text { dan ibu PKK }\end{array}$ & \\
\hline
\end{tabular}




\section{Pembahasan}

\section{A. Program Inti}

1. Pelatihan Pembuatan Hand Sanitizer

Program inti Pelatihan Pembuatan Hand Sanitizer pada masyarakat Desa Tamaila Utara dilakukan dengan tujuan untuk memberikan pengetahuan dan kesiap siagaan diri dalam mencegah penularan Covid-19, yakni dengan memberikan pelatihan tentang cara membuat Hand Sanitizer dari bahan alami yang mudah didapat disekitar lingkungan desa, sehingga masyarakat tidak perlu lagi membeli Hand Sanitizer yang biasa dijual dipasaran.

Sasaran dari patihan ini ialah masyarakat desa dan karang taruna. Kegiatan ini dilaksanakan pada hari Sabtu, 19 September 2020 jam 10.00 WITA s.d selesai, bertempat di Kantor Desa Tamaila Utara.

\section{Pelatihan pembuatan coklat}

Pembuatan cokelat candy sederhana dilaksanakan pada hari Sabtu, 19 September 2020. Pembuatan cokelat candy sederhana ini dihadiri langsung oleh masyarakat Desa Tamaila Utara dengan pemateri langsung dari Dosen Fakultas Pertanian Universitas Negeri Gorontalo. Pembuatan cokelat dilakukan karena dusun Tumba merupakan salah satu dusun yang ada di Desa ini sebagai penghasil cokelat. Namun masyarakatnya tidak mengetahui bagaimana proses pembuatan cokelat siap saji. Dengan adanya pelatihan pembuatan cokelat candy sederhana ini, diharapkan masyarakat akan mengetahui hal terebut. Dimana biji cokelat yang sebelumnya tidak dimanfaatkan menjadi cokelat candy sederhana yang siap dimakan. 
B. Program Tambahan

1. Program sosialisasi PHBS dan Kampanye $3 \mathrm{M}$

Sebagai upaya memperkuat adaptasi kebiasaan baru (New Normal) menuju masyarakat yang produktif dan aman terhadap Covid19 mahasiswa KKN SGP UNG Desa Tamaila Utara Kecamatan Tolangohula menyelenggarakan kegiatan penyuluhan dan sosialisasi Pencegahan Covid-19 pada siswa SD 12 Tolangohula dan SMP SATAP Tamaila Utara. Kegiatan ini dilakukan pada hari Rabu tanggal 09 September 2020. Sosialisasi ini dilakukan dengan tujuan agar para siswa tetap memperhatikan protokol kesehatan di Era New Normal serta dapat menerapkan Perilaku Hidup Bersih dan Sehat sebagai salah satu langkah mencegah penyebaran Covid-19.

\section{Program pelatihan pembuatan coklat}

Kegiatan pelatihan pembuatan sabun ini dilaksanakan pada hari Sabtu, 19 September 2020. Pemateri dari kegiatan ini merupakan dosen Fakultas Pertanian Jurusan Ilmu dan Teknologi Pangan Universitas Negeri Gorontalo yang dihadiri Langsung oleh Masyarakat dan aparat desa Tamaila Utara. Pada kegiatan ini masyarakat sangat antusias dalam mengikuti pelatihan pembuatan sabun ini. Sebelum proses pembuatan sabun, kualitas dari sabun yang dibuat harus secara jelas ditentukan atau diputuskan. Dengan mencampur minyak-minyak atau lemak yang berbeda memungkinkan untuk memperoleh sebuah sabun akhir dengan kualitas yang diharapkan. Parameter mutu yang biasanya diperhatikan adalah: tampilan umum (meliputi kepadatan sabun/compact, bercahaya, kesat), kelarutan yang baik, pembusaan yang baik dan stabil, daya membersihkan tinggi, berbuih, tahan 
terhadap ketengikan (bau tidak sedap), baik dalam air lunak, stabilitas baik (berhubungan dengan warna).

Proses pembuatan sabun ini tidak membutuhkan waktu yang lama akan tetapi sabun yang selesai dibuat masih dalam bentuk cair sehingga belum dapat langsung dipakai. Oleh karena itu, sabun cair tersebut harus didiamkan selama 14 sampai 30 hari dan dibungkus dengan kertas dan bisa juga dengan kain agar menjadi padat sehingga bisa dipakai. Zat aditif yang paling umum ditambahkan dalam pembuatan sabun adalah parfum, pewarna, dan garam ( $\mathrm{NaCl}$ ) namun pada pelatihan ini kami menggunakan coklat sebagai bahan tambahan. Sabun yang dihasilkan pada pelatihan ini merupakan sabun dalam bentuk padat.

\section{Program penataan lingkungan}

Kegiatan pengabdian kepada masyarakat merupakan salah satu wujud kepedulian mahasiswa kepada masyarakat di Desa Tamaila Utara. Kegiatan pengabdian berupa penataan lingkungan untuk menciptakan ruang terbuka hijau guna untuk menciptakan suasana yang lebih indah, nyaman, dan sejuk. Selain itu adanya kegiatan ini dapat meningkatkan keakraban, kebersamaan dan solidaritas dikalangan mahasiswa dan masyarakat di Desa Tamaila Utara. Kegiatan pemeliharaan lingkungan yang berkelanjutan akan dapat menciptakan ruang terbuka hijau yang asri, nyaman dan indah di Desa Tamaila Utara.

\section{Program penataan lingkungan}

Embung Tamaila Utara didirikan pada tahun 2018, embung ini dimasukan di BUMDES ( Badan Usaha Milik Desa) yang dibangun di 
Dusun lloheluma. Embung ini difungsikan sebagai tempat pemancingan. Embung digunakan untuk menjaga kualitas air tanah, mencegah banjir, hingga pengairan. Embung menampung air hujan di musim hujan dan digunakan petani tamaila utara untuk mengairi lahan di musim kemarau.

Embung Tamaila Utara ini direncanakan akan direnovasi pada tahun 2021. Dengan tujuan renovasi Embung Tamaila Utara yaitu dapat difungsikan sebagai tempat wisata dan juga tempat pemancingan. Dalam desain Embung Tamaila Utara terdapat beberapa bangunan untuk dimanfaatkan keberlangsungan pengunjung antara lain jembatan kecil, aula terbuka, gazebo dan rumah tempat peristirahatan/vila mini.

\section{Program PORDES}

Kegiatan Pekan Olahraga Desa Tamaila Utara merupakan kegiatan yang diselenggarakan oleh mahasiswa KKN GEF-SGP Universitas Negeri Gorontalo Gelombang II. Kegiatan ini bertujuan untuk meningkatkan sportifitas dan menjalin tali silaturahmi antar mahasiswa dan masyarakat Desa Tamaila Utara.

Kegiatan Pekan Olahraga Desa Tamaila Utara dilaksanakan mulai tanggal 08-25 Oktober 2020 telah di laksanakan sesuai program yang telah di sepakati bersama. Kegiatan ini di buka untuk umum atau tidak di batasi usia. Anak-anak, remaja,dan orang tua bisa ikut serta. Adapun kegiatan yang dilombakan ialah Sepak Takraw dan Sepak Bola.

\section{KESIMPULAN}

Program yang dilaksanakan tiap perguruan tinggi berbeda-beda tergantung pada disiplin ilmu yang terkait serta kebutuhan masyarakat 
dari daerah yang dituju sebagai tempat pelaksanaan KKN. Program yang dibuat dapat terbagi menjadi program umum seperti peringatan hari besar, pemberdayaan masyarakat, dan program khusus yang terkait tema besar suatu tim KKN.

Program KKN GEF-SGP melalui pelatihan pembuatan hand sanitizer dan pelatihan pembuatan coklat tentunya banyak memberikan manfaat kepada masyarakat desa tamaila utara. Sama halnya Dengan program - program tambahan yang sudah kami laksanakan yakni, pelatihan pembuatan sabun, sosialisai kesehatan, penataan lingkungan, desain embung,dan PORDES menjadi kegiatan pendukung yang kami lakukan untuk melakukan pemberdayaan di masyarakat tamaila utara sehingga masyarakat tetap produktif walau dalam masa pandemi.

\section{UCAPAN TERIMA KASIH}

Ucapan trima kasih Kepada Kepala Desa dan aparat desa Tamaila Utara, yang sudah menerima kami mahasiswa KKN untuk mengabdi di desa tamaila utara, ucapan terima kasih juga kepada masyarakat dan karang taruna desa tamaila utara yang banyak memberikan bantuan tenaga dan juga pikiran kepada kami mahasiswa dalam setiap kegiatan - kegiatan yang kami buat di desa tamaila utara. Semoga apa yang sudah diberikan kepada kami mahasiswa KKN bisa menjadi pengalaman yang baru yang akan kami kenang untuk selamanya. 


\section{REFERENCES}

Hermawan, A., 2007. Pengaruh Ekstrak Daun Sirih terhadap Pertumbuhan Staphylococcus aerus dan Escherichia coli dengan Metode Difusi Disk, Fakultas Kedokteran Hewan Universitas Airlangga, Surabaya.

Notoatmodjo, S., 2010. Metodologi Penelitian Kesehatan, Rineka Cipta, Jakarta.

Sari, Retno., Dewi I. and Noorma R., 2004, Pemanfaatan Sirih sebagai Sediaan Hand Gel Antiseptic : I. Studi Formulasi, Laporan Penelitian, Fakultas Farmasi,Universitas Airlangga

Suharto, 1994, Flora Normal serta Hubungan Kuman dengan Hospes dan Lingkungan, dalam: Mikrobiologi Kedokteran, Edisi Revisi, UI Press, Jakarta, p. 32

Telaumbanua, D. (2020). Urgensi Pembentukan Aturan Terkait Pencegahan Covid-19 di Indonesia. Qalamuna - Jurnal Pendidikan, Sosial, Dan Agama, 12(1), 59- 70. 